Original Research Paper

\title{
Reliability and Economic Analysis of a Power Generating System Comprising One Gas and One Steam Turbine with Random Inspection
}

\author{
Dalip Singh and Gulshan Taneja \\ Department of Mathematics, Maharshi Dayanand University, Rohtak, Haryana, India
}

\author{
Article history \\ Received: 2014-04-05 \\ Revised: 2014-04-26 \\ Accepted: 2014-11-12 \\ Corresponding Author: \\ Dalip Singh, \\ Department of Mathematics, \\ Maharshi Dayanand \\ University, Rohtak, \\ Haryana, India
}

\begin{abstract}
Reliability and economic analysis for a power generating system comprising one gas and one steam turbine has been done wherein the inspection for doing one of the three types of maintenance (Minor, Path or Major) is carried out randomly. Initially, both the units i.e., the gas turbine as well as the steam turbine are operating. On failure of the gas turbine, the system goes to down state, whereas on failure of the steam turbine, the system may be kept in upstate with only gas turbine working if the buyer of the power so generated is ready to pay higher amount or otherwise put to down state. System is analyzed by making use of semi-Markov processes and regenerative point technique. Expressions for the reliability of the system and various measures related to the economy have been obtained and then the expression for profit incurred to the system is also obtained. Study through graphs is made which lead to interesting conclusions. Cut-off points with respect to the revenue per unit up time in both the cases i.e., when the system works in combined cycle and when it works in single cycle have been obtained which help in deciding the minimum price of the electricity produced in such a way so as to get the positive profit.
\end{abstract}

Key words: Gas Turbine, Steam Turbine, Random Inspection, Semi-Markov Processes, Regenerative Point Technique

\section{Introduction}

Today we are surrounded by more powerful systems than ever and they are being constantly and continuously designed and developed. The process and technology is aimed at making our lives smooth though also ends up contributing to making it more complex. The impact of the failure or mismanagement of a power generating and power distribution system in a major city, the malfunction of an air traffic control system at an international airport, miscommunication in today's internet systems or the breakdown of a nuclear power plant is simply frightening. There is too much at stake in terms of cost, human life and national security to take any risks with devices and we cannot afford any malfunctioning, even an accidental one. As a consequence, the importance of reliability at all stages of modern engineering processes, including design, manufacturing, distribution and operation is a must. Reliability models for mechanical and electronic systems have been widely studied in the field of reliability by various researchers including Parashar and Taneja (2007; Taneja and Malhotra, 2013). Contributors for the analysis of reliability models for systems with two similar units include (Tuteja et al., 1991; Rizwan et al., 2010) and Sharma et al. (2011). Systems with two dissimilar units have also been analyzed by numerous researchers including Baohe (1997; Goyal et al., 2011). In most of the studies on two dissimilar units, one unit was taken as operative and other as standby. Both the dissimilar units have also been taken as operative simultaneously in some of the studies. Tuteja et al. (2001) discussed a two-unit system where it has been considered that both the units may be operative at a time and the operation of main unit depends on the subunit, e.g., computer system as main unit and electricity as sub-unit. Two units for the systems discussed by them were totally dissimilar i.e., their nature was different. Here, failure in one unit affects the other but converse does not hold. However, there may be practical situations where the two units are dissimilar but the nature of the work done by them is same; and also failure in either of the units affects the working of the other. Such a situation was observed by the authors when they visited some gas turbine plants. For any country, power generation is not only the back bone of 
economic growth but fulfils the needs of industry, agriculture and house hold systems. But, the effective running of such plants is a big concern to the technical, managerial and administrative set up. Smooth running of a plant depends on the reliability of the systems working therein and their components too. Reliability and economic analysis for such systems considering variation in demand and power production capacity has not been done so far in the field of reliability and our aim is to bridge in such a gap.

The present study is an attempt to investigate the reliability and economic analysis of a gas turbine plant comprising one gas and one steam turbine wherein inspection is carried out at random points of time to detect which one of the three types of maintenance (Minor, Path or Major) needs to be done. Initially, both the units i.e., the gas turbine as well as the steam turbine are operating. On failure of the gas turbine, system goes to down state, whereas on failure of the steam turbine, the system may be kept in the up state with only gas turbine working if the buyer of the power so generated is ready to pay higher amount or otherwise put to down state. When only the gas turbine is operable and the steam turbine is failed and the system is put to operation, this type of working of the system is called working in the Single Cycle; whereas when both the units are operative then it is called the Combined Cycle.

\section{Other Assumptions for the Model:}

- Failure times and time to carry random inspection are assumed to follow exponential distribution whereas the repair times, time of doing inspection and maintenance have arbitrary distributions

- After every repair, unit becomes as good as new

- All the random variables are independent

- System fails completely on the failure of both the units

- System works at reduced capacity when only the gas turbine is operative and such type of working is called single cycle

- System is put to downstate during any inspection and also when steam turbine is failed with no buyer of power generated in single cycle

\section{Materials and Methods}

The reliability modeling and economic analysis have been done by making use of semi-Markov processes and regenerative point technique. Various measures of system effectiveness such as mean time to system failure, availability at full capacity, availability in single cycle, expected down time, expected times for minor, path and major inspection, busy period for repair and expected number of visits have been obtained. Costbenefit analysis has been carried out. Graphical study has been made for a particular case by making use of programming in $\mathrm{C}$ and MS Excel.

\section{Notations}

$\mathrm{O}_{\mathrm{gt}}$ : $\quad$ Gas turbine operative

$\mathrm{O}_{\mathrm{st}}$ : $\quad$ Steam turbine operative

$\mathrm{U}_{\mathrm{rgt}}: \quad$ Gas turbine under repair

$\mathrm{U}_{\mathrm{rst}}$ : $\quad$ Steam turbine under repair

$\mathrm{d}_{\mathrm{gt}}$ : $\quad$ Gas turbine put to down mode

$\mathrm{d}_{\mathrm{st}}$ : $\quad$ Steam turbine put to down mode

$\mathrm{W}_{\mathrm{rgt}}$ : Gas turbine waiting for repair

$\mathrm{U}_{\mathrm{Rst}}$ : Repair of steam turbine continuing from previous state

$\lambda: \quad$ Failure rate of gas turbine

$\alpha: \quad$ Failure rate of steam turbine

P: $\quad$ Probability that there is dire demand of electricity and the customer is ready to pay higher amounts

Q: $\quad$ 1-p i. e the probability that the customer is not ready to pay the amount higher than the normal rates

$\mathrm{g}_{1}(\mathrm{t}), \mathrm{G}_{1}(\mathrm{t})$ : Pdf and cdf of repair time of gas turbine

$\mathrm{g}_{2}(\mathrm{t}), \mathrm{G}_{2}(\mathrm{t})$ : Pdf and cdf of repair time of steam turbine

$h(t), H(t)$ : Pdf and cdf of time for undertaking the system for inspection

$\mathrm{P}_{1}$ : $\quad$ Probability that inspection reveals the need of minor maintenance

$\mathrm{P}_{2}$ : $\quad$ Probability that inspection reveals the need of path maintenance

$\mathrm{P}_{3}$ : $\quad$ Probability that inspection reveals the need of major maintenance

$\mathrm{i}(\mathrm{t})$ : $\quad$ Pdf of inspection time to see which type of maintenance is required

$\mathrm{M}_{\mathrm{Nm}}$ : $\quad$ Minor maintenance going on

$\mathrm{P}_{\mathrm{m}}$ : $\quad$ Path maintenance going on

$\mathrm{M}_{\mathrm{J}_{\mathrm{m}}}$ : $\quad$ Major maintenance going on

$h_{1}(t)$ : Pdf of the time for doing minor maintenance

$h_{2}(t)$ : $\quad$ Pdf of the time for doing path maintenance

$\mathrm{h}_{3}(\mathrm{t})$ : $\quad$ Pdf of the time for doing major maintenance

$\mathrm{U}_{\mathrm{i}}$ : $\quad$ Failed unit under inspection to reveals the type of failure

\section{Transition Probabilities and Mean Sojourn Times}

The transition diagram showing the various states of the system is shown in Fig. 1. The epochs of entry into states $0,1,2,3,5,6,7$ and 8 are regeneration points and thus $0,1,2,3,5,6,7$ and 8 are generative states. State 4 is failed state. States 5, 6, 7 and 8 are down states due to inspection. States 1 and 3 are also down states due to putting the operable unit to down mode and state 2 is single cycle upstate. 


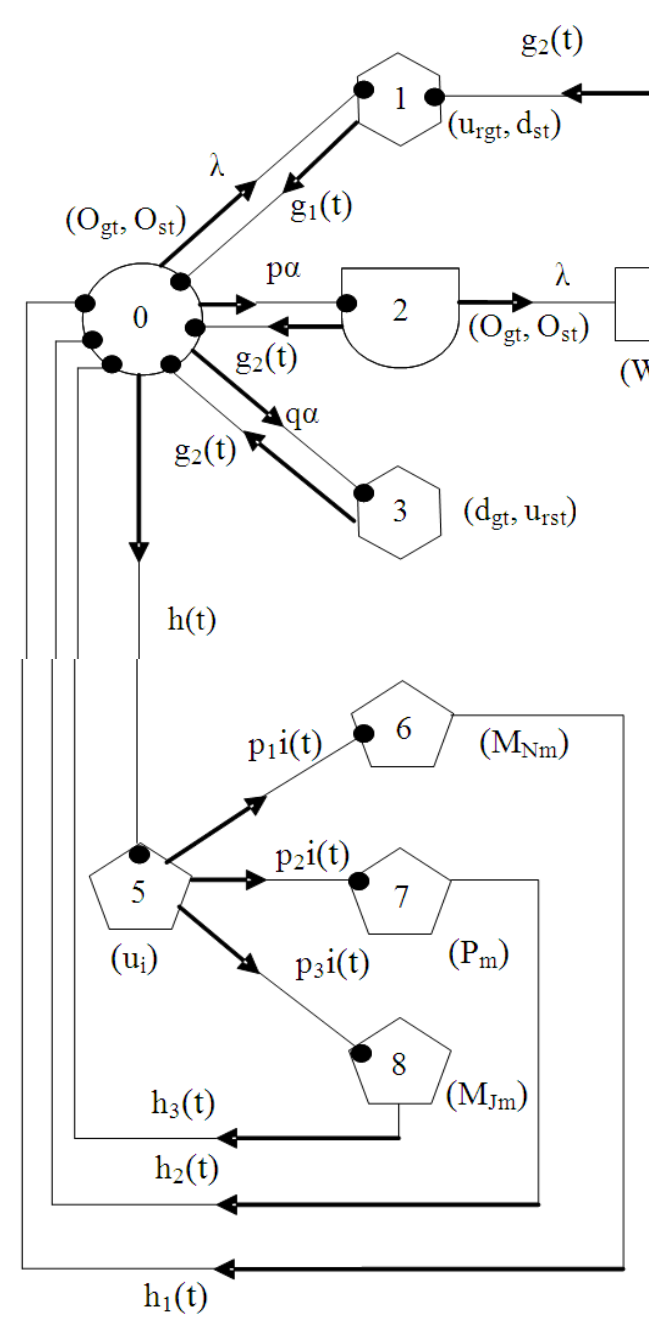

Fig. 1. State transition diagram

The transition probabilities are:

$$
\begin{aligned}
& q_{01}(t)=\lambda e^{-(\lambda+\alpha) t} \bar{H}(t), \quad q_{02}(t)=p \alpha e^{-(\alpha+\lambda) t} \bar{H}(t) \\
& q_{03}(t)=q \alpha e^{-(\alpha+\lambda) t} \bar{H}(t), \quad q_{05}=e^{-(\lambda+\alpha) t} h(t) \\
& q_{10}(t)=g_{1}(t), \quad q_{20}(t)=e^{-\lambda t} g_{2}(t), \quad q_{24}(t)=\lambda e^{-\lambda t} \bar{G}_{2}(t) \\
& q_{21}^{(4)}(t)=\left(1-e^{-\lambda t}\right) g_{2}(t) \\
& q_{30}(t)=g_{2}(t), \quad q_{56}(t)=p_{1} i(t), \quad q_{57}(t)=p_{2} i(t) \\
& q_{58}(t)=p_{3} i(t), \quad q_{60}(t)=h_{1}(t) \\
& q_{70}(t)=h_{2}(t), \quad q_{80}(t)=h_{3}(t)
\end{aligned}
$$

The non-zero elements $p_{i j}$ are given as $p_{i j}=\lim _{s \rightarrow 0} q_{i j}^{*}(s)$.

The mean sojourn time $\left(\mu_{i}\right)$ in the regenerative state $i$ is defined as the time to stay in that state before transition to any other state. If $T$ denotes the sojourn time in the regenerative state $i$, then:

$$
\mu_{i}=E(t)=-\int_{0}^{\infty} p_{\gamma}[t>t] d t
$$

Thus:

$$
\begin{aligned}
& \mu_{0}=\frac{1-h^{*}(\lambda+\alpha)}{\lambda+\alpha}, \mu_{1}=\int_{0}^{\infty} t g_{1}(t) d t, \mu_{2} \\
& =\int_{0}^{\infty} e^{-\lambda t} \bar{G}_{2}(t) d t, \mu_{3}=\int_{0}^{\infty} t g_{2}(t) d t, \mu_{5} \\
& =\int t i(t) d t, \mu_{6}=\int_{0}^{\infty} t h_{1}(t) d t \\
& \mu_{7}=\int_{0}^{\infty} t h_{2}(t) d t, \mu_{8}=\int_{0}^{\infty} t h_{3}(t) d t
\end{aligned}
$$

\section{Mean Time to System Failure}

To determine the Mean Time to System Failure (MTSF) of the system, we regard the failed states as absorbing states. Defining $\phi_{i}(t)$ as the cdf of first passage time from regenerative state $\mathrm{i}$ to failed state and making the probabilistic arguments, we obtain the recursive relation for $\phi_{i}(t)$. Then, the reliability of the system at time $\mathrm{t}$ is given as.

$R(t)=$ the inverse Laplace transform of $\left(1-\phi_{0}^{* *}(s) / s\right)$ and the Mean Time To System Failure (MTSF) when the system starts from the state 0 is given by:

$$
T_{0}=\lim _{s \rightarrow 0} \frac{1-\phi_{0}^{* *}(s)}{s}=\frac{N}{D}
$$

where, $\phi_{0}^{* *}(s)$ is the Laplace-Stieltjes Transform of $\phi_{0}(t)$ :

$$
\begin{aligned}
& N=\mu_{0}+p_{01} \mu_{1}+p_{02} \mu_{2}+p_{03} \mu_{3}+p_{05} \mu_{5} \\
& +p_{05}\left(p_{56} \mu_{6}+p_{57} \mu_{7}+p_{58} \mu_{8}\right),
\end{aligned}
$$

And:

$$
D=p_{02} p_{24}
$$

\section{Availability at Full Capacity}

Let us define $A_{i}(t)$ as the probability that system is up and working in full capacity at the instant $t$ given that system entered regenerative state $i$ at $t=0$. Using the arguments of the theory of regenerative process, the Laplace transform of the availability $A_{0}(t)$ is given by:

$$
A_{0}^{*}(s)=\frac{N_{1}(s)}{D_{1}(s)}
$$

Where:

$$
N_{1}(s)=\frac{\left[1-h^{*}(\lambda+\alpha+s)\right]}{(\lambda+\alpha+s)}
$$

And: 


$$
\begin{aligned}
& D_{1}(s)=\left(1-q_{01}^{*} q_{10}^{*}-q_{02}^{*} q_{20}^{*}-q_{03}^{*} q_{30}^{*}\right. \\
& -q_{05}^{*}\left(q_{56}^{*} q_{60}^{*}+q_{57}^{*} q_{70}^{*}+q_{58}^{*} q_{80}^{*}\right)
\end{aligned}
$$

In steady state, the availability of the system is given by:

$$
A_{0}=\lim _{s \rightarrow 0}\left(s A_{0}^{*}(s)\right)=\frac{N_{1}}{D_{1}}
$$

Where:

$$
N_{1}=\mu_{0}
$$

And:

$$
\begin{aligned}
& D_{1}=\mu_{0}+\mu_{1}\left(p_{01}+p_{02} p_{21}\right)+\left(p_{02}+p_{03}\right) \mu_{3}+ \\
& p_{05} \mu_{5}+p_{05}\left(p_{56} \mu_{6}+p_{57} \mu_{7}+p_{58} \mu_{8}\right)
\end{aligned}
$$

Similarly, we the following measures of system ffectiveness, have been obtained as:

$$
\text { Availability in } \sin \text { gle cycle }\left(A_{0}^{(s)}\right)=\frac{N_{2}}{D_{1}}
$$

Expected down time excluding failed $\operatorname{state}\left(D T_{0}\right)=\frac{N_{3}}{D_{1}}$

Expected time for minor inspection $\left(M I_{0}\right)=\frac{N_{4}}{D_{1}}$

Expected time for path inspection $\left(P I_{0}\right)=\frac{N_{5}}{D_{1}}$

Expected time for major inspection $\left(M J_{0}\right)=\frac{N_{6}}{D_{1}}$

Busy period analysis for repair $\left(B_{0}\right)=\frac{N_{7}}{D_{1}}$

Expected number of visits of the repairman $\left(V_{0}\right)=\frac{N_{8}}{D_{1}}$,

Where:

$$
\begin{aligned}
N_{2}= & p_{02} \mu_{2} \\
N_{3}= & p_{03} \mu_{3}+\left(p_{01}+p_{02} p_{21}^{(4)}\right) \mu_{1}+ \\
p_{05}\left(\mu_{5}+p_{58} \mu_{8}+p_{57} \mu_{7}+p_{56} \mu_{6}\right) & N_{4}=p_{05} p_{56} \mu_{6} \\
& N_{5}=p_{05} p_{57} \mu_{7} \\
& N_{6}=p_{05} p_{58} \mu_{8} \\
N_{7}= & \left(p_{01}+p_{02}+p_{21}^{(4)}\right) \mu_{1}+\left(p_{02}+p_{03}\right) \mu_{3} \\
\mathrm{~N}_{8}= & 1
\end{aligned}
$$

And $D_{1}$ is already specified.

\section{Cost-Benefit Analysis}

Expected profit incurred to the system is the excess of revenue over cost and in steady state, is given by:

$$
\begin{aligned}
& \text { PROFIT }=C_{0} A_{0}+C_{1} A_{0}^{s}-C_{2} D T_{0}-C_{3} M I_{0} \\
& -C_{4} P_{0}-C_{5} M J_{0}-C_{6} B_{0}-C_{7} V_{0}
\end{aligned}
$$

$C_{0}=$ Revenue per unit uptime while working in full capacity

$C_{1}=$ Revenue per unit uptime during working in single cycle

$C_{2}=$ Loss per unit time for which the system is in down state (excluding failed state)

$C_{3}=$ Cost per unit time for which the system is under gone for minor inspection

$C_{4}=$ Cost per unit time for which the system is undergone for path inspection

$C_{5}=$ Cost per unit time for which the major inspection goes on

$C_{6}=$ Cost per unit time for engaging the repairman for doing repair

$C_{7}=$ Cost per visit of the repairman

\section{Results}

The following particular case is considered for numerical calculations:

$$
\begin{aligned}
& h(t) \beta_{e}^{-\beta t}, g_{1}(t)=\delta_{1} e^{-\delta_{1} t}, g_{2}(t)=\delta_{2} e^{-\delta_{2} t} \\
& i(t)=\gamma e^{-\gamma t}, h_{1}(t)=\gamma_{4} e^{-\gamma_{4} t} \\
& h_{2}(t)=\gamma_{5} e^{-\gamma 5 t}, h_{3}(t)=\gamma_{6} e^{-\gamma_{\varepsilon} t}
\end{aligned}
$$

Various estimated values on the basis of gathered information visiting some gas turbine plants are:

$$
\begin{aligned}
& \lambda=0.000023, \beta=0.0001, \delta_{1}=0.042, \delta_{2}=0.042, \gamma \\
& =0.5, \gamma_{4}=0.004, \gamma_{5}=0.042, \gamma_{6}=0.001
\end{aligned}
$$

The assumed values, wherever used, are displayed on figures for graphs. The values of various measures of system effectiveness obtained for this particular case are:

- $\quad$ Mean time to system failure $=919004400 \mathrm{hrs}$

- Availability at full capacity $\left(\mathrm{A}_{0}\right)=0.94674780$

- Availability in single cycle $\left(\mathrm{A}_{0}^{(\mathrm{s})}\right)=0.00004731$

- Expected down time excluding failed state $\left(\mathrm{DT}_{0}\right)=$ 0.05320499

- Expected time for minor inspection $\left(\mathrm{MI}_{0}\right)=$ 0.00946748

- Expectedtime for path inspection $\left(\mathrm{PI}_{0}\right)=$ 0.01420122 
- Expected time for maj or inspection $\left(\mathrm{MJ}_{0}\right)=$ 0.02840243

- Busy period analysis for repair $(\mathrm{B} 0)=0$. 00103877

- Expected number of visits of the repairman $\left(\mathrm{V}_{0}\right)=$ 0.00013538
Figure 2 depicts the behaviour of profit w.r.t. revenue per unit uptime during working in full Capacity $\left(\mathrm{C}_{0}\right)$ for different values of loss during down time $\left(\mathrm{C}_{2}\right)$.

Figure 3 depicts the behaviour of profit w.r.t. revenue per unit uptime in single cycle $\left(\mathrm{C}_{1 \mathrm{~S}}\right)$ for different values of loss during down time $\left(\mathrm{C}_{2}\right)$.

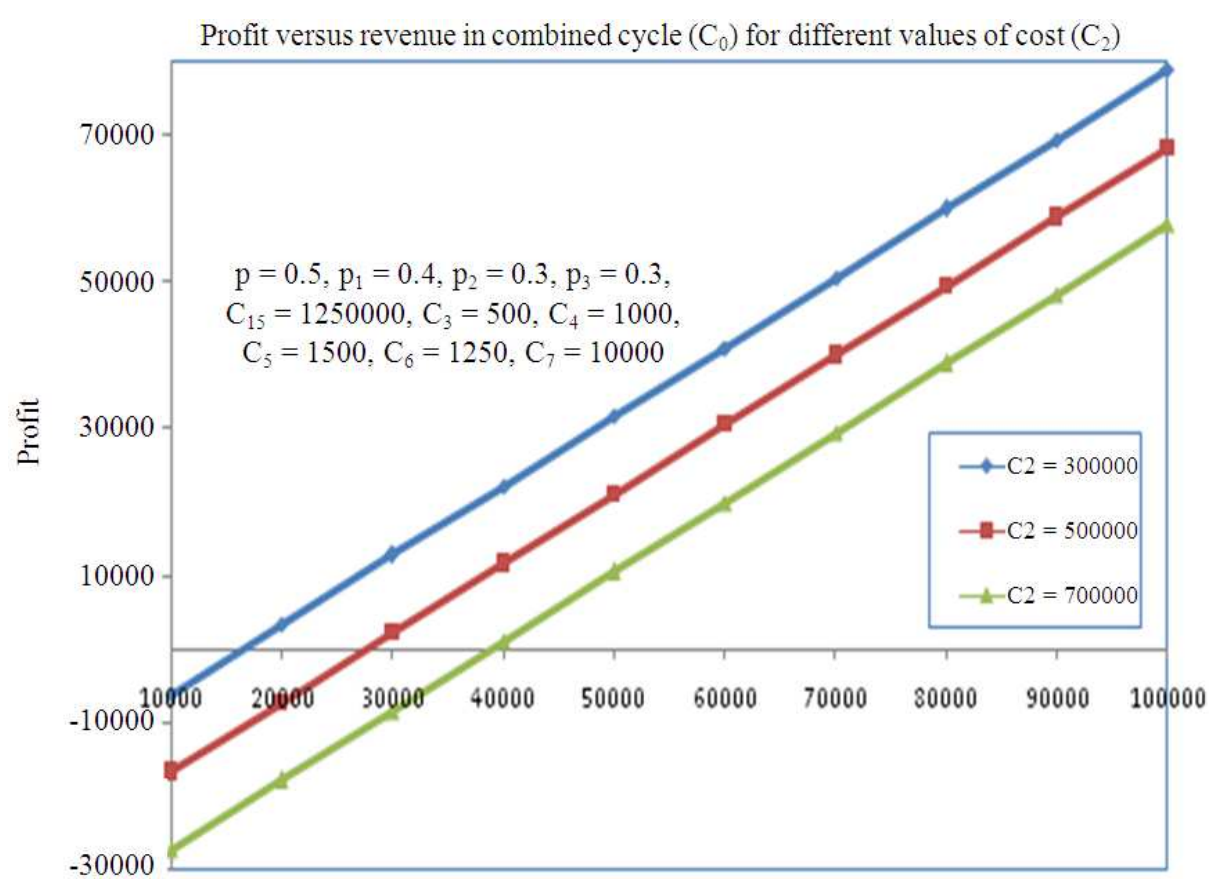

Fig. 2. Profit versus revenue per unit up time in combined cycle

Profit versus revenue in single cycle $\left(\mathrm{C}_{15}\right)$ for different values of cost $\left(\mathrm{C}_{2}\right)$

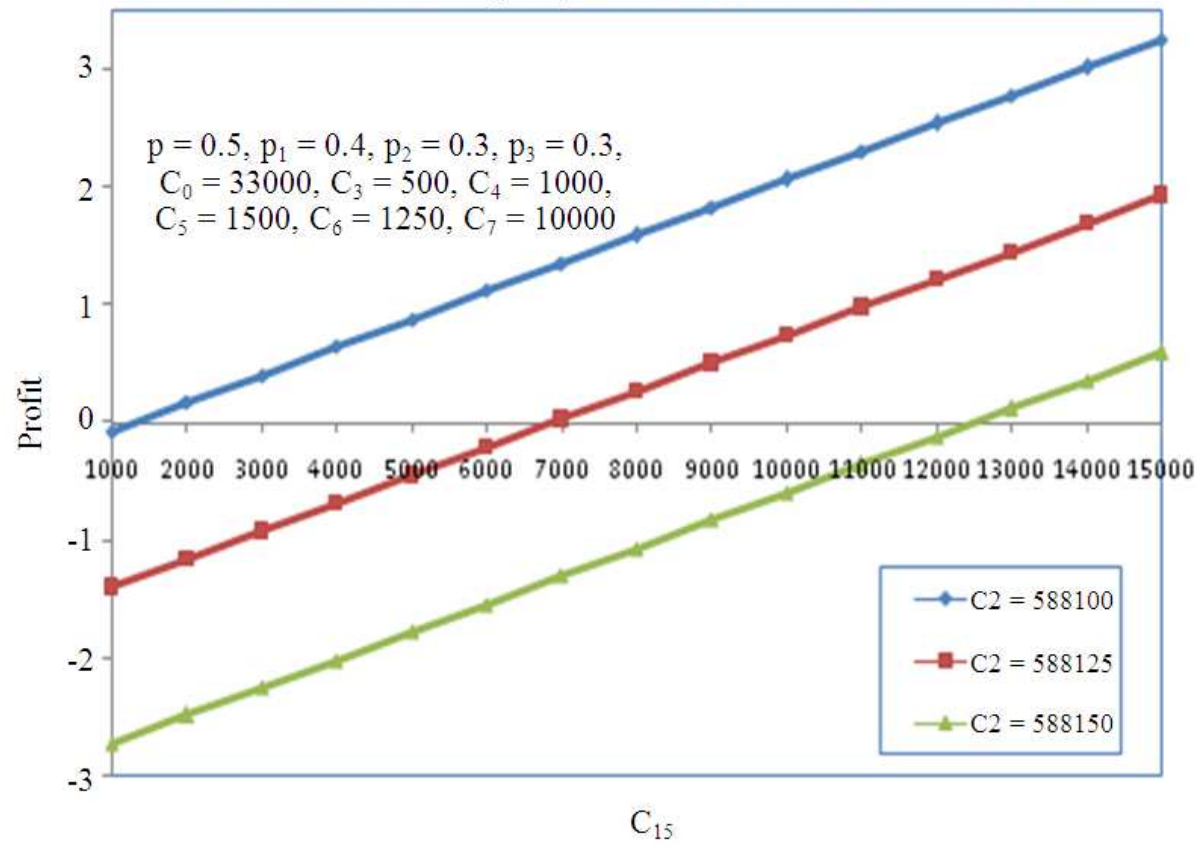

Fig. 3. Profit versus revenue per unit up time in single cycle 
The results obtained in the paper are new as none of the previous study discussed the reliability and economic analysis of two-unit Gas Turbine Power generating system with random inspection. The discussion and conclusion given in the subsequent sections reveal the results are very interesting and useful for the companies producing power through gas turbines.

\section{Discussion}

On the basis of the above results, we can have the following discussion:

- It can be interpreted that the profit increases with increase in the values of $\mathrm{C}_{0}$ and also with $\mathrm{C}_{1 \mathrm{~S}}$

- For $\mathrm{C}_{2}=500000$, profit is positive or zero or negative according as $\mathrm{C}_{0}>$ or $=$ or $<27754.60$ i.e., the price per unit of the electricity should be fixed in such a way so as to give $\mathrm{C}_{0}$ not less than 27754.60 to get positive profit

- For $\mathrm{C}_{2}=700000$, profit is positive or zero or negative according as $\mathrm{C}_{0}>$ or $=$ or $<38954.15$ i.e., the price per unit of the electricity should be fixed in such a way so as to give $\mathrm{C}_{0}$ not less than 38954.15 to get positive profit

- For $\mathrm{C}_{2}=558100$, profit is positive or zero or negative according as $\mathrm{C}_{1 \mathrm{~S}}>$ or $=$ or $<1282.28$ i.e., the price per unit of the electricity should be fixed in such a way so as to give $\mathrm{C}_{1 \mathrm{~S}}$ not less than 1282.28 to get positive profit

- For $\mathrm{C}_{2}=588125$, profit is positive or zero or negative according as $\mathrm{C}_{1 \mathrm{~S}}>$ or $=$ or $<6877.32$ i.e., the price per unit of the electricity should be fixed in such a way so as to give $C_{1 S}$ not less than 6877.32 to get positive profit

- For $\mathrm{C}_{2}=588150$, profit is positive or zero or negative according as $\mathrm{C}_{1 \mathrm{~S}}>$ or $=$ or $<12488.90$ i.e., the price per unit of the electricity should be fixed in such a way so as to give $\mathrm{C}_{1 \mathrm{~S}}$ not less than 12488.90 to get positive profit

\section{Conclusion}

From the analysis done for the model developed in this study, it is concluded that:

- $\quad$ The MTSF and $\mathrm{A}_{0}$ get decreased whereas $\mathrm{AS}_{0}$ gets decreased with increase in the values of the failure rate $(\alpha)$ of steam turbine. But the MTSF has higher values for lower values of probability of demand on higher payment $(\mathrm{p})$ whereas $\mathrm{A}_{0}, \mathrm{AS}_{0}$ have higher values for higher values of $\mathrm{p}$

- $\mathrm{A}_{0}>$ or $=$ or $<\mathrm{AS}_{0}$ according as the failure rate $(\alpha)<$ or $=$ or $>0.080046158$ when $\lambda=0.000023, \beta=0.00001$, $\delta_{1}=0.042, \delta_{2}=0.04, \gamma=0.5, \gamma_{4}=0.004, \gamma_{5}=0.002$, $\gamma_{6}=0.001, \mathrm{p}_{1}=0.4, \mathrm{p}_{2}=0.3, \mathrm{p}_{3}=0.3, \mathrm{p}=0.5$

- The profit decreases as failure rate $(\alpha)$ of steam turbine increases for small values of probability $(p)$. It has higher values for higher values of $\mathrm{p}$. But when the probability (p) is increased up to certain level, the profit increases as failure rate $(\alpha)$ of steam turbine increases. This is because there is greater increase in receiving the number of higher payments for greater values of probability $(\mathrm{p})$

- The profit increases with increase in the values of revenue per unit up time. Cut-off points with respect to the revenue per unit up time have also been obtained which reveal that the revenue per unit up time should not be less than its value at cut-off point. This cut-off point helps the producer to fix the price of the electricity in such a way so as to get the positive profit

The above remarks are based on what computational work has been done in this study. However, if someone is interested in finding some other cut-off points related to the desired rates, costs and probabilities involved, he/she can use the equations obtained for MTSF, measures of system effectiveness and the profit. Then, the expressions particularly for the system under consideration can be obtained putting the numerical values of various rates/costs experienced therein. Graphs can be plotted to find the cut-off points for the concerned rates/costs/revenue which will be helpful in taking important decisions so far as the reliability and the profitability of the system is concerned.

\section{References}

Baohe, S., 1997. On a two-dissimilar unit system with three modes and random check, Microelectron. Reliab., 37: 1233-1238. DOI: 10.1016/S0026-2714(96)00121-7

Goyal, A., G. Taneja and D.V. Singh, 2011. 3-unit system compridsing two types of units with first come first served repair pattern except when both types of units are waiting for repair, J. Math. Stat., 6: 316-320. DOI: 10.3844/jmssp.2010.316.320

Parashar, B. and G. Taneja, 2007. Reliability and profit evaluation of a PLC hot standby system based on a master slave concept and two types of repair facilities. IEEE Trans. Reliab, 56: 534-539.

DOI: 10.1109/TR.2007.903151

Rizwan, S.M., V. Khurana and G. Taneja, 2010. Reliability analysis of a hot standby industrial system. Int. J. Model. Simulat., 30: 315-322. DOI: $10.2316 /$ Journal.205.2010.3.205-5057 
Sharma, U., Rekha and G. Taneja, 2011. Analysis of a two-unit standby oil delivering system with a provision of a switching over to another system at need to increase the availability, J. Math. Stat., 7: 57-60. DOI: $10.3844 /$ jmssp.2011.57.60

Taneja, G. and R. Malhotra, 2013. Cost-benefit analysis of a single unit system with scheduled maintenance and variation in demand. J. Math. Stat., 9: 155-160. DOI: $10.3844 /$ jmssp.2013.155.160
Tuteja, R.K., R.T. Arora and G. Taneja, 1991. Analysis of two-unit system with partial failures and three types of repair. Reliability Eng. Syst. Safety, 33: 199-214. DOI: 10.1016/0951-8320(91)90059-G

Tuteja, R.K., U. Vashistha and G. Taneja, 2001. Costbenefit of a system where operation and some times repair of main unit depends on sub-unit. Pure Appllied Math. Sci., 3: 41-61. 